\section{Discussion}

In this case the mitral stenosis resulted from subvalvular fusion and marked foreshortening of the chordae tendineae. This tethered the anterior leaflet to both papillary muscles and the posterior leaflet to the posterior wall of the left ventricle, resulting in a severe conical fixed and restricted valve orifice. This was believed not to be rheumatic because the leaflets were completely normal.

The variety of congenital mitral valve abnormalities ranges from repairable cleft leaflets to restrictive and challenging lesions of isolated mitral stenosis. ${ }^{3}$ Most patients with isolated congenital mitral stenosis have severe symptoms in early childhood. ${ }^{1,2}$ These patients often require early surgical management. When symptoms are mild or even moderate, the operation is delayed in the hope that in the future an adult-sized device can be used. ${ }^{1}$ In patients with congenital mitral valve disease, reconstructive surgery is the primary goal. When necessary, valve replacement can be performed safely with relatively low morbidity and mortality and can provide relief of symptoms for many patients. ${ }^{1,2,4}$ However, mitral valve repair is preferable when feasible to limit implantation of prosthetic material and reduce the need for future reoperation. Also, mitral valve repair reduces the need for long-term anticoagulation and might provide more physiologic correction of the lesion. Our report is notable because of the novel use of neochordae to both leaflets for the repair.

\section{References}

1. Serraf A, Zoghbi J, Belli E, et al. Congenital mitral stenosis with or without associated defects: an evolving surgical strategy. Circulation. 2000;102:166-71.

2. Kadoba K, Jonas RA, Mayer JE, Castaneda AR. Mitral valve replacement in the first year of life. J Thorac Cardiovasc Surg. 1990;100:762-768.

3. Cetin G, Ozkara A, Mert AM, Hatemi AC, Oztunc F, Guven O. Supraannular mitral valve replacement in a child with congenital mitral stenosis. Anadolu Kardiyol Derg. 2004;4:175-7.

4. Günther T, Mazzitelli D, Schreiber C, et al. Mitral-valve replacement in children under 6 years of age. Eur J Cardiothorac Surg. 2000;17:426-430.

\title{
A novel approach to the surgical correction of scimitar syndrome
}

\author{
Tuan T. Lam, MD, Brian L. Reemtsen, MD, Vaughn A. Starnes, MD, and Winfield J. Wells, MD, Los Angeles, Calif
}

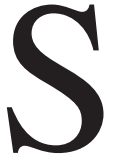

cimitar syndrome is a congenital cardiac malformation in which pulmonary flow from the right lung is partially or totally drained via a venous channel that joins the inferior vena cava (IVC), usually just below the level of the diaphragm. ${ }^{1}$ Options for repair include the creation of a long baffle from the orifice of the scimitar vein within the IVC to the atrial septal defect (ASD) that directs the anomalous pulmonary venous flow to the left atrium, ${ }^{2}$ division with reimplantation of the scimitar vein into the right atrium with an intra-atrial baffle that directs blood flow through an ASD to the left atrium, ${ }^{3}$ partitioning of the IVC into anterior and posterior compartments with a pericardial baffle that channels pulmonary venous blood flow directly into the left atrium, ${ }^{4}$ or direct anastomosis of the divided scimitar vein to the left atrium. ${ }^{5}$ These techniques may be complicated by obstruction of the scimitar vein owing to either baffle thrombosis or kinking of the venous channel. We describe an alternative method for repair of scimitar syndrome using a short polytetrafluoroethylene (Gore-Tex; W. L. Gore \& Associates Inc, Flagstaff, Ariz) interposi-

From the Department of Cardiothoracic Surgery, University of Southern California, Children's Hospital of Los Angeles, Los Angeles, Calif.

Received for publication Oct 6, 2006; accepted for publication Oct 16, 2006.

Address for reprints: Winfield J. Wells, MD, Department of Cardiothoracic Surgery, Children's Hospital of Los Angeles, 4650 Sunset Blvd, Mailbox 66, Los Angeles, CA 90054 (E-mail: wwells@chla.usc.edu).

J Thorac Cardiovasc Surg 2007;133:573-4

$0022-5223 / \$ 32.00$

Copyright () 2007 by The American Association for Thoracic Surgery

doi:10.1016/j.jtcvs.2006.10.021 tion tube graft to ensure freedom from tension or kinking when directly connecting the scimitar vein to the left atrium.

\section{Clinical Summary}

Two patients aged 4 and 14 years have undergone repair for scimitar syndrome with a pulmonary venous extension technique. Both patients had the entire venous return from the right lung via the scimitar vein with a relatively short length of vein from the hilum of the lung to the junction with the IVC. Both patients had a secundum ASD. Preoperative echocardiogram showed right atrial and ventricular dilation. Cardiac catheterization demonstrated the anomalous pulmonary venous return from the right lung associated with an ASD. The pulmonary/systemic flow ratio was 2.6:1 (4-year-old) and 1.4:1 (14-year-old).

Cardiopulmonary bypass with bicaval cannulation was established through a median sternotomy. The patients were cooled before aortic crossclamping and administration of cold blood cardioplegic solution. The scimitar vein was isolated from its point of emergence from the pulmonary parenchyma to its junction with the IVC near the reflection of the diaphragm. Despite dividing the scimitar vein flush with the IVC, there was concern that a direct anastomosis to the left atrium would create acute angulation and kinking. Therefore, a short polytetrafluoroethylene interposition graft (12-mm in the 4-year-old and 16-mm in the 14-year-old) was sewn end to end to the divided scimitar vein; then, through a right atriotomy and via the ASD, the rightward superior lateral aspect of the left atrium was probed and an atriotomy was made. The polytetrafluoroethylene interposition graft was cut to appropriate length and anastomosed end to side to the left atriotomy (Figure 1). The ASD was closed with an autologous pericardial patch. After repair, an 


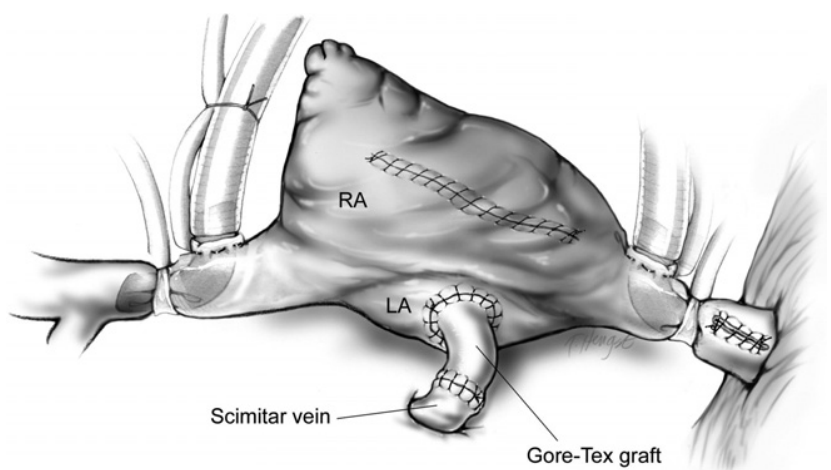

Figure 1. The scimitar vein has been divided from the inferior vena cava and is anastomosed to the left atrium using a polytetrafluoroethylene (Gore-Tex) graft extension. $R A$, Right atrium; $L A$, left atrium.

intraoperative transesophageal echocardiogram showed unobstructed return from the scimitar vein. Postoperative recovery was uneventful.

Follow-up echocardiograms at 4 and 6 months have shown unobstructed laminar flow from the scimitar vein to the left atrium and regression of right atrial and ventricular dilation in both patients.

\section{Discussion}

Techniques available to repair scimitar syndrome commonly use some type of baffle that channels pulmonary venous blood flow through an ASD to the left atrium. In general, these baffle techniques are technically more complicated to perform and there is a potential for baffle thrombosis. ${ }^{1}$
The group from Indiana University School of Medicine has described direct anastomosis of the scimitar vein to the left atrium as the procedure of choice. ${ }^{5}$ They prefer a right thoracotomy approach and have reported on 12 patients with this technique without stenosis of the reimplanted scimitar vein. Of note, none of their patients had a concomitant ASD, which they suggest could be managed from the right thoracotomy approach.

Our experience suggests that there may be some patients in whom, despite maximal mobilization of the scimitar vein, direct connection to the left atrium may result in tension, angulation, or kinking. Such patients will benefit from venous extension with an interposition graft. Experience with polytetrafluoroethylene graft extension of the IVC in the extracardiac Fontan procedure has shown the durability of synthetic graft extension of venous channels. Although long-term follow-up is needed, we anticipate the same good outcome with interposition grafts in the pulmonary venous system.

\section{References}

1. Brown JW, Gudjonsson U. Scimitar syndrome. Semin Thorac Cardiovasc Surg Pediatr Card Surg Ann. 2006;9:56-62.

2. Zubiate P. Surgical correction of anomalous pulmonary venous connection. Ann Surg. 1962;156:234-50.

3. Shumaker HB Jr, Judd D. Partial anomalous pulmonary venous return with reference to drainage into the inferior vena cava and to an intact atrial septum. J Cardiovasc Surg (Torino). 1964;5:271-8.

4. Calhoun RF, Mee RBB. A novel operative approach to scimitar syndrome. Ann Thorac Surg. 2003;76:301-3.

5. Brown JW, Ruzmetov M, Minnich DJ, Vijay P, Edwards CA, Uhlig PN, et al. Surgical management of scimitar syndrome: an alternative approach. J Thorac Cardiovasc Surg. 2003;125:238-45. 